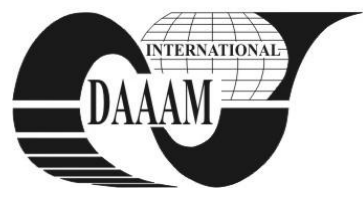

Annals of DAAAM for 2011 \& Proceedings of the 22nd International DAAAM Symposium, Volume 22, No. 1, ISSN 1726-9679 ISBN 978-3-901509-83-4, Editor B. Katalinic, Published by DAAAM International, Vienna, Austria, EU, 2011 Make Harmony between Technology and Nature, and Your Mind will Fly Free as a Bird Annals \& Proceedings of DAAAM International 2011

\title{
PARTIAL DISCHARGE ACTIVITY OF THERMALLY AGED STATOR WINDING BARS
}

\author{
MRAZ, P[etr]; MENTLIK, V[aclav] \& PIHERA, J[osef]
}

\begin{abstract}
This paper deals with partial discharge activity of stator winding of large rotating electrical machines. Discharge activity is one of the most degradable factors of electrical machines (rotating and non-rotating machines (transformers) as well. The paper describes mainly partial discharge activity measurement and its subsequent interpretation. Monitoring of discharge activity helps to predict the lifetime, dependability and the period of revisions of electrical machines. In the paper are remarked the most important and valuable monitoring parameters of partial discharge activity. Finally an example of concretely measurement and evaluation is mentioned.
\end{abstract}

Key words: discharge activity, partial discharges, large rotating machines, stator winding

\section{INTRODUCTION}

Lifetime of electrical machines and devices is mainly given by its insulating system. The system is reliable as much as its weakest part. Also in this case that well-known rule has to be considered. Because of that is necessary to focus on those parts and try to improve them. In general the lifetime of insulating systems is observed by laboratory tests.

Insulating systems of electric machines contains a lot of spatial nonuniformity, which getting bigger and larger during its lifetime. Just these nonuniformities caused the partial discharge activity which supports electrical treeing (Mentlík, 2006). Those processes have very negative influence on the reliability and lifetime of the whole electric machine. Also the surface discharge activity can be observed in insulating systems. Namely it is slot discharges and gliding (creeping) discharges, which appears in heads of winding.

This paper deals with testing of insulating systems by accelerated aging, which caused gradual degradation of it. These changes can analysed by measuring and observing several parameters. A lot of interesting and important information can be obtained by measuring absorption and resorptive characteristics. Next used measuring parameter is dissipation factor $\tan \delta$. And the last but not least, the partial discharge activity measurement is used for diagnostic of insulating systems (Mentlík et al., 2008).

Thanks to these measurements and continuous monitoring of insulating systems of the machine, it is possible to prevent unplanned repairs and lay-offs. It is possible to plan the repairs and maintenance in advance according to the current state. Next the lifetime and causes of the failures can be predicted as well.

\section{PARTIAL DISCHARGE MEASRUMENT}

Determination of characteristic values is essential for evaluation of partial discharges. There are several measured and derived parameters that characterize the nature of partial discharges. These parameters are defined in norm ČSN EN 60270: Technique of high voltage testing - Measurement of partial discharges, took over from the international norm IEC IEC 60270:2000 (ČSN EN 60270).

The measurement of a frequently appeared level of charge that is quantitatively the highest was based on the chapter 4.3.3 Response to the impulse sequence for measurement of the apparent charge (ČSN EN 60270). It was labelled Qiec and the unit was picocoulombs (pC).

The frequency of pulses $n$ that is the mean value of a current impulses count, which was caused by discharge activity during a certain time, was recorded afterwards. The unit of impulse count was an impulse/second. The only impulses recorded are those above the particular level of noise. In this case the threshold of the noise was $15 \mathrm{pC}$.

The voltage levels associated with partial discharges are important for the subsequent evaluations. It is crucial to properly define the test voltage of partial discharges in advance. The high level was set to be $10 \mathrm{kV}$ and the low level to be 5 $\mathrm{kV}$. The high level $10 \mathrm{kV}$ corresponded to operating voltage of a turbo-generator which was $13.8 \mathrm{kV}$. This level was chosen because of the bars were measured in the open area (unwedged and unfixed in the machine). The determination of low level was based on the begging of the partial discharge activity.

The inception voltage of partial discharges $U i$ was the lowest level of voltage during which the partial discharges begin to appear stably. The inception voltage was measured by continuous increasing of test voltage as long as the intensity of discharges got over the minimum level of noise. Its unit is kilovolts (kV) (Mentlík et al., 2006).

Extinguish voltage of partial discharges $U e$ is the opposite of the inception voltage. It is a level of voltage in kilovolts as well, during which the intensity of partial discharges got under the level of noise (Mentlík et al., 2006).

\section{METHODOLOGY OF PARTIAL DISCHARGE OBSERVING}

The measurement took place on the bars of stator winding after their removal from the turbo-generator. First it was necessary to clean them, to remove their upper low-conductive layer and to prepare the electrodes for measurement. The bars were cut into 14 samples (divided into three groups) with the same length $(80 \mathrm{~cm})$ for easier manipulation. Those located in the machine with the null potential are labelled null in the graphs. The samples made of phase potential bars are labelled as phase and the last two samples were changed after 15 years of use during the regular maintenance, which means they were newer than the rest of samples and they are labelled as changed. The samples were thermal aged in the temperature of $180^{\circ} \mathrm{C}$ in period 4, 12, 24, 36, 52, 70, 100 and 130 hours. Digital measuring system PD SMART (LDIC LEMKE Company) was used for measuring partial discharge activity. The system was calibrated before the each measurement by calibrating device LDIC LDC-5/S3 (the reference charge was $500 \mathrm{pC}$ ). Measured frequency range was $100 \mathrm{kHz}-500 \mathrm{Khz}$. 


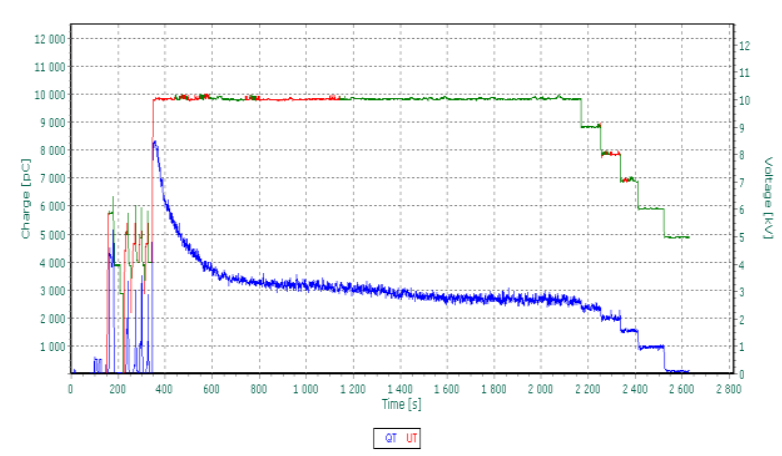

Fig. 1. Time dependence of measurement process

First of all, the inception $U i$ and extinguish $U e$ voltage was measured in five repeating steps. That was made because of statistical evaluation. After that the highest test voltage level

was set at $10 \mathrm{kV}$. Then it took 30 minutes to observe selfextinguish phenomenon. The phenomenon means that the intensity of partial discharges settles down and usually gets down to a stable level. Afterwards the measuring voltage was decreasing by $1 \mathrm{kV}$ till reached the set level $(5 \mathrm{kV})$. The whole process (for a sample 164_1, thermal aged 130 hours) is recorded in figure 1, where the clear exponential decrease of the partial discharges intensity is shown. Recorded waveform was not the same for all specimens. In case of change bars the exponential decreased was mostly observe, whereas the phase and null bars did not show any decrease in a procedure. This phenomenon is the subject of another research. In figure 1 the left vertical axis shows the apparent charge Qiec (pC) and the right vertical axis shows test voltage in kilovolts. Horizontal axis represents the time period measured in seconds. The graph displays step decrease of discharges together with test voltage.

There is a lot of experience needed for analysing of the results of partial discharge activity. Evaluation needs long term measurements that are very sensitive about the chosen methodology (Stone et al., 2004). Generally the measurement of partial discharges by this way is very sensitive to external disturbance. Figure 2 shows the worsening trend of inception voltage $U i$. The samples of higher quality have higher inception voltage $U i$.

Time dependence of Qiec is represented in figure 3. Increasing trend of partial discharges with decrease in the final point can be observed on samples made from changed bars. The rest of specimens are nearly constant. The interesting fact is that the changed samples demonstrate a higher partial discharge level after 52 hours of aging.

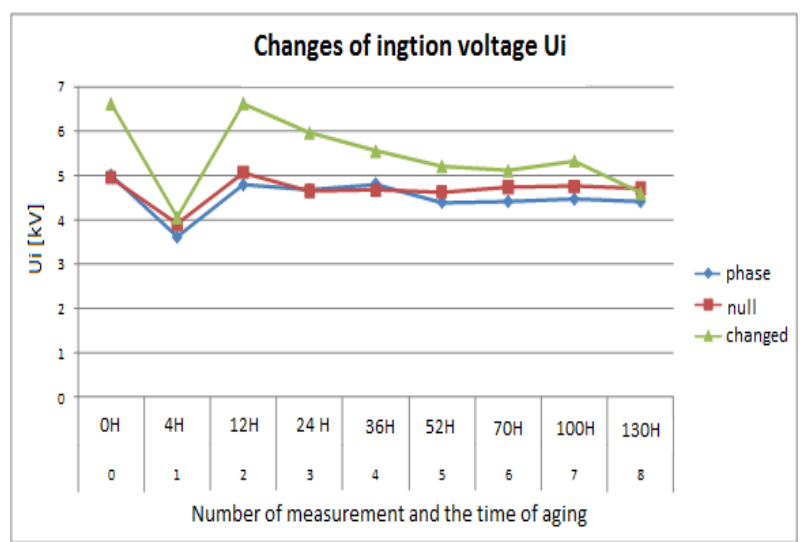

Fig. 2. Changes of ignition voltage $U i$

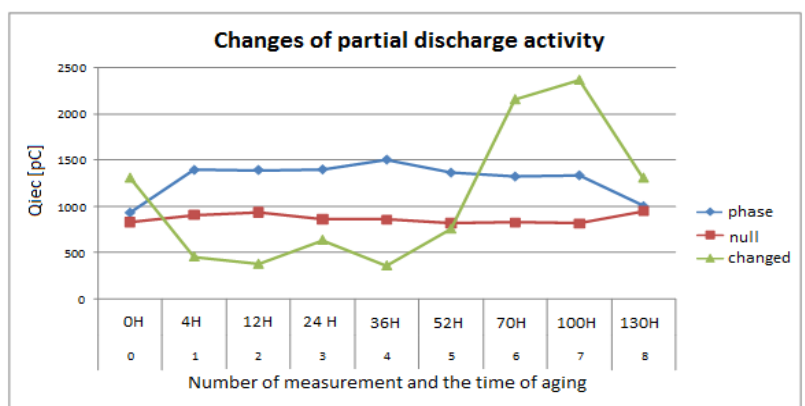

Fig. 3. Changes of partial discharge activity

\section{CONCLUSION}

The conclusion is that during the thermal aging the inception voltage has fallen off trend, which means worsening state of the insulating system. The measurement of apparent charge Qiec and count of discharge impulses show that the changed bars have higher partial discharge activity from 52 hours of thermal aging. There is a sign of inconvenient storage of the spare bars (lately changed bars). Furthermore it should be caused by the different stage of hardening of resin into the insulating system of the bars (Hudon et al., 2008).

The sensitivity to external noise effects was apparent during the measuring process. Even though the measurement took place in a shielded laboratory the device detected different impulses of external disturbance. For example the switching-on of any power device in the room next door. During the measurement the level noise was changing. Mean value of the noise was 15 pC. Next step in this experiment will be comparison between additional electrical parameters (dissipation factor, capacity, polarization and depolarization current) and the results obtained from partial discharge measurements. Final goal will be to determinate the lifetime of the material.

\section{ACKNOWLEDGEMENTS}

This article was carried out with the support of Ministry of Education, Youth and Sports of Czech Republic, MSM 4977751310.

\section{REFERENCES}

ČSN EN 60270. Technika zkoušek vysokým napětim - Měření částečných výbojů

Hudon, C., Belec, M. (2005). Partial discharge signal interpretation for generator diagnostics, IEEE Transactions on Dielectrics and Electrical Insulation, April 2005, Volume: 12 , Issue: 2, p. 297-319

Mentlík, V.; Trnka, P.; Prosr, P.; Pihera, J.; Polanský, R. (2006) Electrical insulation material parameters and power electronic waveform environment, Electrical Insulation, Conference Record of the 2006 IEEE International symposium on electrical insulation, Toronto, ISSN 1089084X, ISBN 1-4244-0333-2, p. 245-248, Toronto, Ontario

Mentlík, V. (2006). Dielektricképrvky a systémy,BEN technická literatura, ISBN 80-7300-189-6, Praha

Mentlík, V., et al. (2008). Diagnostikaelektrickýchzařizení, BEN - technická literatura, ISBN 978-80-7300-232-9, Praha

Stone, G. C.; Boulter, E. A.; Culbert, I.; Dhirani, H.. (2004). Electrical insulation for rotating machines - Design, Evaluation, Aging, Testing and Repair, Wiley IEEE Press, ISBN 0-471-44506-7, United States of America 